\title{
Cephalometric abnormalities in non-obese and obese patients with obstructive sleep apnoea
}

\author{
H. Sakakibara, M. Tong, K. Matsushita, M. Hirata, Y. Konishi, S. Suetsugu
}

Cephalometric abnormalities in non-obese and obese patients with obstructive sleep apnoea. H. Sakakibara, M. Tong, K. Matsushita, M. Hirata, Y. Konishi, S. Suetsugu. (C)ERS Journals Ltd 1999.

ABSTRACT: The aim of this work was to comprehensively evaluate the cephalometric features in Japanese patients with obstructive sleep apnoea (OAS) and to elucidate the relationship between cephalometric variables and severity of apnoea.

Forty-eight cephalometric variables were measured in 37 healthy males and 114 male OSA patients, who were classed into 54 non-obese (body mass index (BMI) $<27$ $\mathrm{kg} \cdot \mathrm{m}^{-2}$, apnoea-hypopnoea index $(\mathrm{AHI})=\mathbf{2 5 . 3} \pm \mathbf{1 6 . 1}$ events $\left.^{-1}{ }^{-1}\right)$ and 60 obese $(\mathrm{BMI} \geq 27$ $\mathrm{kg} \cdot \mathrm{m}^{-2}, \mathrm{AHI}=\mathbf{4 5 . 6} \pm \mathbf{2 8 . 0}$ events $\left.\cdot \mathrm{h}^{-1}\right)$ groups. Diagnostic polysomnography was carried out in all of the OSA patients and in 19 of the normal controls.

The non-obese OSA patients showed several cephalometric defects compared with their BMI-matched normal controls: 1) decreased facial A-P distance at cranial base, maxilla and mandible levels and decreased bony pharynx width; 2 ) enlarged tongue and inferior shift of the tongue volume; 3 ) enlarged soft palate; 4) inferiorly positioned hyoid bone; and 5) decreased upper airway width at four different levels. More extensive and severe soft tissue abnormalities with a few defects in craniofacial bony structures were found in the obese OSA group. For the non-obese OSA group, the stepwise regression model on AHI was significant with two bony structure variables as determinants: anterior cranial base length (S-N) and mandibular length (Me-Go). Although the regression model retained only linear distance between anterior vertebra and hyoid bone (H-VL) as an explainable determinant for AHI in the obese OSA group, H-VL was significantly correlated with soft tissue measurements such as overall tongue area (Ton), inferior tongue area (Ton2) and pharyngeal airway length (PNS-V).

In conclusion, Japanese obstructive sleep apnoea patients have a series of cephalometric abnormalities similar to those described in Caucasian patients, and that the aetiology of obstructive sleep apnoea in obese patients may be different from that in non-obese patients. In obese patients, upper airway soft tissue enlargement may play a more important role in the development of obstructive sleep apnoea, whereas in non-obese patients, bony structure discrepancies may be the dominant contributing factors for obstructive sleep apnoea.

Eur Respir J 1999; 13: 403-410.

Over the last two decades, numerous data have been accumulated from cephalometric analyses of patients with sleep-disordered breathing (SDB). Certain forms of craniofacial anatomical defects, including mandibular deficiency, soft palate enlargement and inferior displacement of the hyoid bone have been suggested as predisposing factors to upper airway obstruction during sleep [1-5]. However, discrepancies exist among the different series as to the relative importance of soft tissue and bony structure defects in the development of SDB [6]. Earlier observations were generally made on small sample groups without adequate control groups. Several investigators recently examined cephalometric abnormalities in SDB patients in a more systemic way [5-8], however, the possible influence of age and body mass index (BMI) on cephalometric measurements was frequently neglected. A more recent study [9] covered the difference in upper airway morphology between snorers and patients with obstructive sleep apnoea (OSA) with respect to age and BMI. However, no normal control group was employed and only a few cep-
Division of Respirology and Allergology, Dept of Internal Medicine, Fujita Health University, School of Medicine, Toyoake, Japan.

Correspondence: H. Sakakibara

Division of Respirology and Allergology Dept of Internal Medicine

Fujita Health University

School of Medicine

1-98 Dengakugakubo

Kutsukake-Cho

Toyoake, Aichi 470-11

Japan

Fax: 81562933576

Keywords: Cephalometry obesity

obstructive sleep apnoea

sleep-disordered

upper airway

Received: February 281998

Accepted after revision October 61998 halometric variables were analysed. In addition, only a few cephalometric studies of Asian SDB patients have been reported in the English literature. It is thought that Asian SDB patients may present some cephalometric features that differ from features in Caucasian patients due to racial physical differences.

Therefore, the present work was undertaken to evaluate comprehensively the cephalometric features between normal subjects and OSA patients in a Japanese population and to elucidate the relationship between cephalometric variables and apnoea severity in non-obese and obese patients with OSA.

\section{Materials and methods}

\section{Subjects}

One hundred and fourteen consecutive male Japanese patients with OSA were enrolled in this study after giving 
informed consent. All were habitual snorers with OSA (age: $49 \pm 13$ yrs; BMI: $27.6 \pm 5.5 \mathrm{~kg} \cdot \mathrm{m}^{-2}$; apnoea-hypopnoea index (AHI): $36.0 \pm 25.2$ events $\cdot \mathrm{h}^{-1}$; oxygen saturation nadir: $69.9 \pm 15.0 \%$ ). Patients were considered to have OSA if they had $\geq 5$ episodes of apnoea + hypopnoea per hour during an overnight polysomnographic study. Twelve female patients with OSA diagnosed during the study period were excluded, and five male OSA patients whose cephalograms could not be obtained were also excluded. Sleep study and lateral cephalometry were performed in all of the patients. Before the diagnostic polysomnography was performed, a questionnaire [10] pertaining to snoring, sleep disturbances and daytime hypersomnolence was completed by each patient, and habitual snoring was judged through a subjective report of the problem by spouses or household members. The 114 OSA patients were classed into two subgroups according to BMI: non-obese OSA $\left(\mathrm{BMI}<27 \mathrm{~kg} \cdot \mathrm{m}^{-2}\right)$ and obese OSA $\left(\mathrm{BMI} \geq 27 \mathrm{~kg} \cdot \mathrm{m}^{-2}\right)$.

Thirty-seven normal males (age: $36 \pm 11$ yrs; BMI: $22.0 \pm$ $2.0 \mathrm{~kg} \cdot \mathrm{m}^{-2}$ ) were recruited as controls. All of the control subjects completed the same questionnaire as the OSA patients. The criteria for selection of the normal controls were good health, a BMI $<27 \mathrm{~kg} \cdot \mathrm{m}^{-2}$, the absence of any subjective symptoms and abnormal laboratory findings related to OSA (AHI $<5$ events $\cdot \mathrm{h}^{-1}$ and oxygen saturation nadir $>90 \%$ ). Age, BMI and sleep data of these two groups of patients and of the normal subjects are presented in table 1. AHI and oxygen saturation nadir in the control group $(\mathrm{n}=19)$ were $0.7 \pm 1.0$ events $\cdot \mathrm{h}^{-1}\left(0-2.1\right.$ events $\left.\cdot \mathrm{h}^{-1}\right)$ and $93.4 \pm 1.8 \%(96-91 \%)$, respectively. There were no significant differences in the BMI between the non-obese OSA and the control group. This study was approved by the ethics committee of the Fujita Health University Hospital.

\section{Polysomnography}

In all 114 of the OSA patients and in 19 of the 37 normal subjects, a sleep study was performed by one-night polysomnographic examination, including electroencephalogram (EEG; C3-A2, C4-A1, O2-A1 and O3A2), bilateral electro-oculogram (EOG), chin electromyogram (EMG), nasal and mouth airflow, electrocardiogram (ECG), thoracic and abdominal respiratory movements by inductive plethysmography and oxygen saturation by finger oximetry. The EEG, EOG, EMG and ECG tracings were recorded on an EEG recorder (5210 System; Nihon Kohden,

Table 1. - Demographic and sleep data for normal subjects, and obese and non-obese patients with obstructive sleep apnoea (OSA)

\begin{tabular}{|c|c|c|c|}
\hline Characteristics & $\begin{array}{c}\text { Normal } \\
\text { controls } \\
n=37\end{array}$ & $\begin{array}{c}\text { Non-obese } \\
\text { OSA } \\
n=54\end{array}$ & $\begin{array}{c}\text { Obese } \\
\text { OSA } \\
n=60\end{array}$ \\
\hline Age yrs & $36.2 \pm 11.4$ & $51.2 \pm 13.0 * * *$ & $46.4 \pm 11.8 * * *$ \\
\hline $\mathrm{BMI} \mathrm{kg} \cdot \mathrm{m}^{-2}$ & $22.2 \pm 2.4$ & $23.4 \pm 2.3$ & $31.4 \pm 4.8 * * *+$ \\
\hline AI events $\cdot h^{-1}$ & $0.3 \pm 0.9^{\#}$ & $21.8 \pm 17.0 * * *$ & $41.3 \pm 27.8^{* * *}+$ \\
\hline AHI events $\cdot h^{-1}$ & $0.7 \pm 1.0^{\#}$ & $25.3 \pm 16.1 * * *$ & $45.6 \pm 28.0 * * *,+$ \\
\hline $\begin{array}{l}\text { Lowest } \mathrm{O}_{2} \\
\quad \text { saturation \% }\end{array}$ & $93.4 \pm 1.8^{\#}$ & $75.7 \pm 12.1 * * *$ & $64.9 \pm 15.6^{* * *}{ }^{+}$ \\
\hline
\end{tabular}

***: $p<0.001$, compared with normal controls; ${ }^{+}: \mathrm{p}<0.001$, compared with non-obese OSA; $:$ n=19; BMI: body mass index; AI: apnoea index; AHI: apnoea-hypopnoea index.
Tokyo, Japan) at a paper speed of $15 \mathrm{~mm} \cdot \mathrm{s}^{-1}$. All of the other parameters were integrated using a Respisomnograph (Non-invasive Monitoring Systems, Miami, FL, USA) and recorded on an 8-channel strip recorder (7758B System, Yokokawa-Hewlett Packard, Tokyo, Japan) at a paper speed of $1 \mathrm{~mm} \cdot \mathrm{s}^{-1}$. Sleep position and body movement were monitored by video and recorded manually. Episodes of apnoea were defined as complete cessation of airflow for $\geq 10 \mathrm{~s}$, and hypopnoea consisted of a $>50 \%$ reduction in oronasal airflow with a decrease in arterial oxygen saturation $\left(\mathrm{Sa}_{2} \mathrm{O}_{2}\right)$ measured by pulse oximetry of at least $4 \%$. Apnoea events were classified as obstructive, mixed or central according to the presence or the absence of breathing efforts with thoracoabdominal paradox. The AHI was defined by the frequency of these events per hour during an overnight polysomnography.

\section{Cephalometry}

A lateral cephalogram was obtained for each subject. The cephalograms were taken on image plates (ST-V, Fuji Medical System Inc, Tokyo, Japan) with the subject in the sitting position, at a film focus distance of $2 \mathrm{~m}$, left to right view. Exposures were made at $75 \mathrm{kV}$ and $250 \mathrm{~mA}$ at the end-expiratory phase during quiet breathing, and a cephalostat was used to keep the subject's head in such a position that the Frankfort horizontal line was parallel to the ground during exposure. Images of the cephalograms were digitized and input into a computer, previewed and processed for sharp visibility of both the soft tissues and the bony structures and printed out through a computed radiography system (FCR 7000, Fuji Medical Systems Inc.). Images were then stored on a Macintosh (LC575) computer (Apple Japan Inc., Tokyo, Japan) and analysed using the public domain National Institutes of Health (NIH) Image program (developed at the U.S. National Institutes of Health and available through the Internet by anonymous FTP from zippy.nimh.nih.gov). Forty-eight variables representing both craniofacial skeletal and soft tissue morphology and the head posture were measured by a single observer (M. Tong). Every measurement was taken three times by the observer in a single-blind manner, and the mean value of the two nearest measurements was used in the statistical analyses to ensure reliability. The cephalometric landmarks and reference lines are defined in table 2 and illustrated anatomically in figure 1 . The following angles, dimensions and areas were measured: SNA, the angle between S-N and N-A; SNB, the angle between S-N and N-B; ANB, the angle between N-A and $\mathrm{N}-\mathrm{B}$; SNPg, the angle between S-N and N-Pg; NS/Ver, the angle between S-N and true vertical; NL/Ver, the angle between NL and true vertical; NS/OPT, the angle between S-N and OPT, FH/OPT, the angle between FH and OPT; NL/OPT, the angle between NL and OPT; OPT/ Hor, the angle between OPT and true horizontal; CVT/ Hor, the angle between CVT and true horizontal; OPT/ CVT, the angle between OPT and CVT, NSBa (cranial base flexture)[11], the angle between $\mathrm{S}-\mathrm{N}$ and a line from $\mathrm{S}$ to $\mathrm{Ba} ; \mathrm{BMeH}$, the angle between $\mathrm{B}-\mathrm{Me}$ and $\mathrm{Me}-\mathrm{H}$; S$\mathrm{Ba}$, the distance between $\mathrm{S}$ and $\mathrm{Ba} ; \mathrm{N}-\mathrm{Ba}$, the distance between $\mathrm{N}$ and $\mathrm{Ba}$; $\mathrm{N}-\mathrm{Me}$, the distance between $\mathrm{N}$ and $\mathrm{Me}$; S-Go, the distance between S and Go; N-ANS, the distance between $\mathrm{N}$ and ANS; ANS-Me, the distance between ANS and Me; S-Ar, the distance between S and 
Table 2. - Definitions of cephalometric landmarks and reference lines

\begin{tabular}{|c|c|}
\hline Landmarks and reference lines & Definitions \\
\hline $\mathrm{S}$ & sella, midpoint of the fossa hypophysealis \\
\hline $\mathrm{N}$ & nasion, anterior point at the frontonasal suture \\
\hline ANS & anterior nasal spine, most anterior point of the nasal spine \\
\hline PNS & posterior nasal spine, most posterior point of the nasal spine \\
\hline Or & orbitale, deepest point on the infra-orbital margin \\
\hline Po & porion, upper point on the bony ear opening \\
\hline A & deepest anterior point in the concavity of the anterior maxilla \\
\hline B & deepest anterior point in the concavity of the anterior mandible \\
\hline Go & $\begin{array}{l}\text { gonion, a mid-plane point at the gonial angle located by bisecting the posterior and inferior } \\
\text { borders of the mandible }\end{array}$ \\
\hline $\mathrm{Me}$ & menton, most inferior point of the bone chin \\
\hline Ar & articulare, posterior point at the intersection of the posterior ramus with the inferior cranial base \\
\hline $\mathrm{Ba}$ & basion, most postero-inferior point on the clivus \\
\hline AA & anterior atlas \\
\hline G & most posterior point on the symphysis of the mandible \\
\hline $\mathrm{Pg}$ & prognathion, most anterior point on the symphysis of the mandible \\
\hline $\mathrm{P}$ & lowest point of the soft palate \\
\hline Ule & upper incisal edge \\
\hline Lle & lower incisal edge \\
\hline TT & most anterior point of the tip of the tongue \\
\hline $\mathrm{C} 3$ & most anterior and inferior point of the 3rd cervical vertebral body \\
\hline $\mathrm{C} 4$ & most anterior and inferior point of the 4 th cervical vertebral body \\
\hline $\mathrm{H}$ & most antero-superior point of the hyoid \\
\hline V & most antero-inferior point of the epiglottic fold \\
\hline ET & epiglottis tip \\
\hline Z & crossing point of the MP and a line connecting $\mathrm{G}$ and $\mathrm{H}$ \\
\hline NS & nasion-sella line, a line through $\mathrm{N}$ and $\mathrm{S}$ \\
\hline FH & Frankfort horizontal line, a line through Or and Po \\
\hline NL & nasal line, a line through ANS and PNS \\
\hline MP & mandibular plane, a plane constructed from Me through Go \\
\hline VL & a line across $\mathrm{C} 3$ and $\mathrm{C} 4$ \\
\hline OPT & $\begin{array}{l}\text { odontoid process tangent, a line across the most superior and posterior point and the most } \\
\text { inferior and posterior point of the axis }\end{array}$ \\
\hline CVT & $\begin{array}{l}\text { cervical vertebra tangent, a line across the most superior and posterior point of the axis and the } \\
\text { most inferior and posterior point of the } 4 \text { th cervical vertebra }\end{array}$ \\
\hline
\end{tabular}

Ar; Ar-Go, the distance between Ar and Go; S-N, the distance between $\mathrm{S}$ and $\mathrm{N}$; ANS-PNS, the distance between ANS and PNS; Me-Go, the distance between Me and Go; G-VL, the linear distance along a perpendicular plane from $\mathrm{G}$ to VL, TGL, the distance between $\mathrm{V}$ and $\mathrm{TT}$, TGH, the linear distance along the perpendicular bisector of the V-TT line to the tongue dorsum; PNS-P, the distance between PNS and P; MPT, the greatest thickness of the soft palate; PNS-Ba (bony nasopharynx) [7], the distance between PNS and Ba; PNS-AA (bony oropharynx) [7], the distance between PNS and AA; AW(PNS$\mathrm{Ba}$ ), the airway width along PNS-Ba; AW1, the narrowest part of airway between PNS and P; AW2, the narrowest part of airway between $\mathrm{P}$ and Go; AWET, the airway width along a line through ET and parallel to the ground; PNS-V, the distance between V and PNS; MP-H, the linear distance along a perpendicular plane from $\mathrm{H}$ to $\mathrm{MP}$; $\mathrm{H}-\mathrm{VL}$, the linear distance along a perpendicular plane from $\mathrm{H}$ to VL, ST(PNS-Ba), the soft tissue thickness measured along PNS-Ba; Max, the area of the maxilla defined by the lines connecting PNS, UIe and ANS; Man, the area of the mandible defined by the lines connecting Go, Me and LIe; Ton, the whole tongue, i.e. the area of the tongue measured at its superior limits and the lines connecting TT, G, H and V; Ton1, upper part of the tongue, i.e. the area of the tongue measured at its superior limits and the lines connecting TT, G, Z and Go; Ton2, lower part of the tongue, i.e. the area of the tongue measured at its posterior limits and the lines connecting Go, Z, H and V; Soft P, the area of the soft palate; Oral C, the area of the oral cavity defined between PNS, A, Me, Go and PNS; and Orop, the area of the oropharynx between the horizontal line through PNS and another horizontal line through the tip of the epiglottis.

\section{Intra- and interobserver reliability of the cephalometry}

The reliability of cephalometric measurements was estimated by calculating the coefficients of variation $(\mathrm{CV})$ for eight selected variables in 10 OSA patients. The following variables were chosen to encompass the different kinds of measurements: S-N and N-Me (simple linear measurements); Max and Ton (area measurements); SNB, SNPg and NS/OPT (angular measurements); and MP-H (complex linear measurements). Measurements on the same cephalogram were repeated by a single observer (M. Tong) three times within 1 day (intraobserver time-to-time CV) and on three separate days at 1-week intervals (intraobserver day-to-day $\mathrm{CV}$ ). The $\mathrm{CV}$ of three measurements was calculated for each patient according to the following formula: $\mathrm{CV}=$ standard deviation $\times 100 /$ mean, and the mean $\mathrm{CV}$ for all of the 10 patients was subsequently obtained. Interobserver reliability of cephalometric measurements was estimated by calculating the $\mathrm{CV}$ value obtained from 


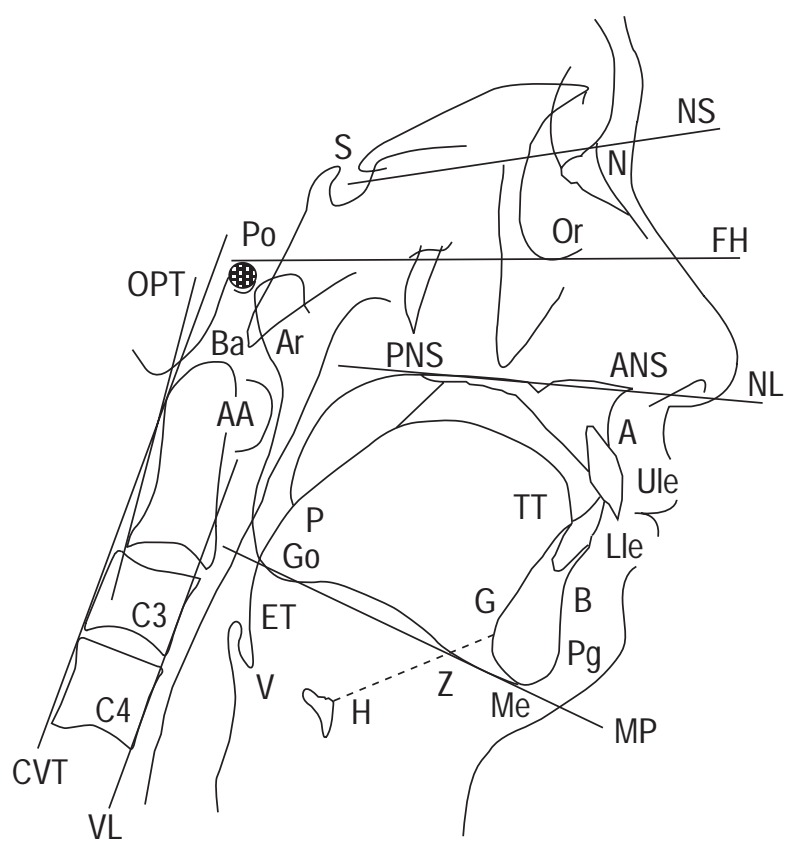

Fig. 1. - Cephalometric landmarks and reference lines. For definitions see table 2 .

seven respiratory disease specialists who measured eight selected variables in 10 OSA patients. Five of the seven specialists had no prior experience in cephalometric analysis, and were trained in computer-assisted cephalometry for $1 \mathrm{~h}$ before obtaining data on the 10 OSA patients.

\section{Statistics}

Firstly, to investigate the effects of age and BMI on cephalometric measurements, Pearson correlation coefficient analysis was performed between age and the cephalometric variables, and BMI and the cephalometric variables in OSA patients. Secondly, considering the influence of BMI on the cephalometric measurements, the OSA population was further classed into an obese and non-obese OSA group by BMI using the cut-off point of $<27$ and $\geq 27 \mathrm{~kg} \cdot \mathrm{m}^{-2}$. Analysis of variance (ANOVA) was performed on the cephalometric variables for each of these two groups and the normal controls. The Bonferroni test was used for multiple comparisons when the ANOVA was significant. Thirdly, correlations between apnoea severity (AHI) and the cephalometric variables were assessed first in the overall OSA group and then in the obese and non-obese OSA groups. A multiple, stepwise, linear regression analysis was also performed to identify which variables best explained the variance in AHI. The dependent variable was the AHI, and independent variables which were correlated with AHI in Pearson analysis were integrated into the model. Only the variables with an F-value $>4$ were finally kept in the formula. Results are expressed as the percentage of the variance of the AHI explained by the formula. This analysis was performed for the overall OSA patients and for each predefined subgroup of BMI.

The results are expressed as mean \pm SD. All of the statistical analyses were performed using a Macintosh-compatible software program (Statview 4.5J, Hulinks Inc., Tokyo,
Japan). Statistical significance was assessed at $\mathrm{p}<0.02$ and $\mathrm{p}<0.05$ for the ANOVA and linear correlation tests, respectively.

\section{Results}

\section{Reliability of the cephalometry}

The reliability estimation of the cephalometric measurements is summarized in table 3. Generally, both the timeto-time $\mathrm{CV}$ and the day-to-day $\mathrm{CV}$ for the intraobserver reliability estimation were very low, with the highest value being 3.04\% for the MP-H measurement, indicating that the measurements by the single observer were highly reproducible. The interobserver reliability was also satisfactory with the greater CV values being $5.29 \%$ for the Max and $4.77 \%$ for the MP-H.

Linear correlation between age, BMI and cephalometric measurements

For the entire OSA group, no cephalometric variable was found to be correlated with age. As expected, BMI was significantly correlated with both AHI $(\mathrm{r}=0.525, \mathrm{p}<$ $0.0001)$ and lowest $\mathrm{Sa}, \mathrm{O}_{2}(\mathrm{r}=-0.335, \mathrm{p}=0.003)$. Seven cephalometric variables were shown to be correlated with BMI, i.e. G-VL ( $\mathrm{r}=0.606, \mathrm{p}<0.0001), \mathrm{H}-\mathrm{VL}(\mathrm{r}=0.469, \mathrm{p}<$ $0.0001)$, Ton $(\mathrm{r}=0.380, \mathrm{p}<0.0001)$, PNS-AA $(\mathrm{r}=0.61, \mathrm{p}<$ $0.0001)$, SNA $(\mathrm{r}=0.328, \mathrm{p}=0.0004)$, SNB $(\mathrm{r}=0.321, \mathrm{p}=$ $0.0006)$, and TGL ( $\mathrm{r}=0.317, \mathrm{p}=0.0009)$.

Comparison of cephalometric measurements: normal versus non-obese OSA

Tables 4-6 summarize the ANOVA results for the cephalometric measurements in the three groups of subjects. Compared with the BMI-matched normal subjects, the

Table 3. - Reliability estimation of the cephalometry

\begin{tabular}{|c|c|c|c|}
\hline \multirow[b]{2}{*}{ Parameters } & \multicolumn{2}{|c|}{ Intraobserver reliability } & \multirow{2}{*}{ 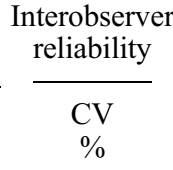 } \\
\hline & $\begin{array}{c}\text { Time-to-time CV } \\
\%\end{array}$ & $\begin{array}{c}\text { Day-to-day CV } \\
\%\end{array}$ & \\
\hline \multicolumn{4}{|c|}{ Simple linear measurement } \\
\hline $\mathrm{N}-\mathrm{Me}$ & $0.20 \pm 0.19$ & $0.49 \pm 0.31$ & $0.72 \pm 0.33$ \\
\hline S-N & $0.43 \pm 0.31$ & $0.73 \pm 0.49$ & $1.43 \pm 0.40$ \\
\hline \multicolumn{4}{|c|}{ Area measurement } \\
\hline $\operatorname{Max}$ & $1.55 \pm 0.92$ & $2.82 \pm 1.61$ & $5.29 \pm 2.08$ \\
\hline Ton & $1.91 \pm 0.98$ & $2.98 \pm 2.82$ & $2.48 \pm 0.92$ \\
\hline \multicolumn{4}{|c|}{ Angular measurement } \\
\hline SNB & $0.48 \pm 0.22$ & $0.77 \pm 0.39$ & $1.49 \pm 0.88$ \\
\hline SNPg & $0.44 \pm 0.29$ & $0.63 \pm 0.72$ & $1.89 \pm 1.35$ \\
\hline NS/OPT & $0.43 \pm 0.20$ & $0.76 \pm 0.32$ & $1.74 \pm 0.85$ \\
\hline \multicolumn{4}{|c|}{ Complex linear measurement } \\
\hline MP-H & $3.04 \pm 1.90$ & $2.96 \pm 4.34$ & $4.77 \pm 1.96$ \\
\hline
\end{tabular}

CV: coefficient of variance. Max: the area of the maxilla defined by the lines connecting PNS, UIe and ANS; Ton: the whole tongue; SNB: the angle between S-N and N-B; SNPg: the angle between S-N and N-Pg. For other definitions see table 2 and text. 
Table 4. - Craniofacial bony structure variables in normal controls, and obese and non-obese obstructive sleep apnoea (OSA) patients

\begin{tabular}{lccc}
\hline Parameters & $\begin{array}{c}\text { Normal } \\
\text { controls } \\
\mathrm{n}=37\end{array}$ & $\begin{array}{c}\text { Non-obese } \\
\text { OSA } \\
\mathrm{n}=54\end{array}$ & $\begin{array}{c}\text { Obese } \\
\text { OSA } \\
\mathrm{n}=60\end{array}$ \\
\hline $\mathrm{SNA}^{\circ}$ & $82.5 \pm 4.3$ & $82.1 \pm 4.6$ & $83.7 \pm 4.0$ \\
$\mathrm{SNB}^{\circ}$ & $78.8 \pm 3.4$ & $77.7 \pm 4.6$ & $79.2 \pm 4.1$ \\
$\mathrm{ANB}^{\circ}$ & $3.6 \pm 2.7$ & $4.5 \pm 2.7$ & $4.6 \pm 2.7$ \\
$\mathrm{SNPg}^{\circ}$ & $79.7 \pm 3.3$ & $77.9 \pm 4.3$ & $78.9 \pm 4.2$ \\
$\mathrm{G}^{\circ} \mathrm{VL} \mathrm{mm}$ & $76.2 \pm 8.2$ & $67.6 \pm 6.9^{+}$ & $74.1 \pm 6.5^{* * *}$ \\
$\mathrm{NS} / \mathrm{Ba}$ & $131.0 \pm 4.6$ & $129.8 \pm 6.8$ & $129.8 \pm 6.5$ \\
$\mathrm{~N}-\mathrm{Ba} \mathrm{mm}$ & $109.7 \pm 6.4$ & $106.5 \pm 6.6$ & $110.8 \pm 6.5^{* * *}$ \\
$\mathrm{~S}-\mathrm{N} \mathrm{mm}$ & $73.5 \pm 3.4$ & $69.6 \pm 3.8^{+}$ & $71.9 \pm 3.8^{* * *}$ \\
$\mathrm{~S}-\mathrm{Ba} \mathrm{mm}$ & $48.0 \pm 5.5$ & $47.4 \pm 6.1$ & $49.8 \pm 5.5$ \\
ANS-PNS mm & $54.5 \pm 4.4$ & $51.5 \pm 5.1^{+}$ & $52.6 \pm 5.0$ \\
Me-Go mm & $77.0 \pm 5.5$ & $73.3 \pm 5.3$ & $75.0 \pm 5.6$ \\
N-Me mm & $138.8 \pm 6.6$ & $139.2 \pm 6.9$ & $140.4 \pm 7.2$ \\
N-ANS mm & $61.2 \pm 3.5$ & $59.5 \pm 3.5$ & $59.8 \pm 4.2$ \\
ANS-Me mm & $79.9 \pm 5.0$ & $81.7 \pm 6.0$ & $82.7 \pm 5.7$ \\
S-Go mm & $92.5 \pm 5.5$ & $91.6 \pm 7.7$ & $94.3 \pm 9.2$ \\
S-Ar mm & $41.5 \pm 3.9$ & $40.6 \pm 4.1$ & $40.8 \pm 3.7$ \\
Ar-Go mm & $56.1 \pm 5.4$ & $54.7 \pm 7.1$ & $56.7 \pm 6.5$ \\
Max mm ${ }^{2}$ & $918 \pm 108$ & $858 \pm 145$ & $913 \pm 157$ \\
Man mm & $1891 \pm 200$ & $1830 \pm 228$ & $1890 \pm 205$ \\
PNS-Ba mm & $50.5 \pm 4.9$ & $46.7 \pm 5.5^{+}$ & $49.1 \pm 4.7^{* * *}$ \\
PNA-AA mm & $40.0 \pm 4.6$ & $35.4 \pm 4.9^{+}$ & $37.3 \pm 4.6^{+, \#}$ \\
Oral C mm ${ }^{2}$ & $4303 \pm 451$ & $4073 \pm 516$ & $4246 \pm 495$ \\
\hline
\end{tabular}

${ }^{+}: \mathrm{p}<0.001$, compared with normal controls; $* * *: \mathrm{p}<0.001$, compared with non-obese OSA; ${ }^{\#}: \mathrm{p}<0.02$, compared with nonobese OSA. For definitions see table 2 and text.

non-obese OSA patients showed the following craniofacial anatomical defects: 1) a decreased facial A-P distance at the cranial base, maxilla and mandible levels as measured by S-N, ANS-PNS and Me-Go, respectively; 2) an enlarged tongue. Of particular interest was the finding that the inferior tongue (Ton2, the part of the tongue outside the oral cavity) was significantly enlarged in the OSA patients whereas the portion of the tongue within the oral cavity (Ton 1) was normal in size; 3 ) an enlarged soft palate, chiefly due to an increase in its length; 4) an inferiorly positioned hyoid bone, as indicated by the MP-H and $\mathrm{BMeH}$ measurements; 5) a decreased anteroposterior width of the bony nasopharynx and oropharynx (PNS-Ba and PNS-AA); 6) a decreased anteroposterior upper airway diameter at four different levels, and a reduced oropharynx area (Orop); 7) retrognathia and/or micrognathia expressed as a short G-VL; and 8) an elongated oropharynx (PNS-V).

Comparison of cephalometric measurements: normal versus obese OSA

Most of the above-mentioned soft tissue and airway abnormalities were also found in the obese OSA patients when compared with the normal subjects, with the exception of only one variable, AWET. In addition, the obese OSA patients had longer tongues (TGL), anteriorly displaced hyoid bones (H-VL) and thicker soft tissues on the nasopharynx wall (ST(PNS-Ba)) than the normal subjects. As for bony structures, the only abnormality found in the obese OSA patients was a relatively narrow bony oropharynx (PNS-AA).
Table 5. - Soft tissue variables, hyoid bone positions and pharyngeal dimensions in normal controls, and obese and non-obese obstructive sleep apnoea (OSA) patients

\begin{tabular}{lccc}
\hline Parameters & $\begin{array}{c}\text { Normal } \\
\text { controls } \\
\mathrm{n}=37\end{array}$ & $\begin{array}{c}\text { Non-obese } \\
\text { OSA } \\
\mathrm{n}=54\end{array}$ & $\begin{array}{c}\text { Obese } \\
\text { OSA } \\
\mathrm{n}=60\end{array}$ \\
\hline Soft tissues & & & \\
PNS-P mm & $39.0 \pm 4.8$ & $41.7 \pm 7.2^{\ddagger}$ & $42.9 \pm 5.7^{+}$ \\
MPT mm & $11.3 \pm 2.2$ & $12.0 \pm 3.3$ & $12.4 \pm 1.8$ \\
Soft P mm & $336 \pm 76$ & $411 \pm 121^{+}$ & $444 \pm 92^{+}$ \\
TGL mm & $83.9 \pm 7.0$ & $85.7 \pm 7.2$ & $89.4 \pm 6.4^{+, * * *}$ \\
TGH mm & $39.7 \pm 4.2$ & $41.9 \pm 4.8^{\ddagger}$ & $43.4 \pm 4.3^{+}$ \\
Ton mm & $3454 \pm 413$ & $3781 \pm 447^{+}$ & $4035 \pm 401^{+, * * *}$ \\
Ton1 mm & $2879 \pm 383$ & $2888 \pm 430$ & $3035 \pm 337$ \\
Ton2 mm & $575 \pm 222$ & $892 \pm 310^{+}$ & $1000 \pm 317^{+}$ \\
ST(PNS-Ba) mm & $23.6 \pm 6.1$ & $27.4 \pm 7.6$ & $31.7 \pm 7.2^{+, \#}$ \\
Hyoid bone & & & \\
positions & & & \\
MP-H mm & $14.0 \pm 6.4$ & $21.9 \pm 8.2^{+}$ & $23.2 \pm 6.9^{+}$ \\
H-VL mm & $40.2 \pm 4.3$ & $40.9 \pm 5.2$ & $45.0 \pm 4.7^{+}, * * *$ \\
BMeH & $103.5 \pm 11.3$ & $119.9 \pm 13.4^{+}$ & $122.3 \pm 12.7^{+}$ \\
Pharyngeal & & & \\
dimensions & & & \\
AW(PNS-Ba) mm & $26.9 \pm 4.5$ & $19.3 \pm 6.0^{+}$ & $17.4 \pm 6.6^{+}$ \\
AW1 mm & $11.0 \pm 4.4$ & $6.5 \pm 3.0^{+}$ & $6.9 \pm 3.0^{+}$ \\
AW2 mm & $12.4 \pm 4.4$ & $7.8 \pm 2.8^{+}$ & $9.1 \pm 3.3^{+}$ \\
AWET mm & $14.8 \pm 5.6$ & $11.0 \pm 4.0^{+}$ & $12.9 \pm 5.0$ \\
PNS-V mm & $73.5 \pm 5.8$ & $82.9 \pm 6.3^{+}$ & $81.9 \pm 7.4^{+}$ \\
Orop mm ${ }^{-2}$ & $760 \pm 223$ & $572 \pm 184^{+}$ & $630 \pm 198^{+}$ \\
\hline t & & &
\end{tabular}

${ }^{+}: \mathrm{p}<0.001$, compared with normal controls; ${ }^{*}: \mathrm{p}<0.02$, compared with normal controls; $* * *: \mathrm{p}<0.001$, compared with nonobese OSA; ${ }^{\#}: \mathrm{p}<0.02$, compared with non-obese OSA. For definitions see table 2 and text

Comparison of cephalometric measurements: non-obese $O S A$ versus obese $O S A$

When compared with the non-obese OSA patients, several cephalometric features were found in the obese OSA patients: 1) an increased tongue length and area; 2) thicker soft tissue in the nasopharynx wall; 3) an anteriorly displaced hyoid bone; and 4) increased craniocervical angulation (NS/OPT, FH/OPT and NL/OPT) and decreased cervical-horizontal angulation (OPT/Hor and CVT/Hor). The non-obese group had a shorter G-VL, a shorter cranial base (N-Ba and $\mathrm{S}-\mathrm{N})$ and a narrower bony nasopharynx and oropharynx (PNS-Ba and PNS-AA) than the obese group.

Table 6. - Head posture variables in normal controls, and obese and non-obese obstructive sleep apnoea (OSA) patients

\begin{tabular}{lcrc}
\hline Parameters & $\begin{array}{c}\text { Normal } \\
\text { controls } \\
\mathrm{n}=37\end{array}$ & $\begin{array}{c}\text { Non-obese } \\
\text { OSA } \\
\mathrm{n}=54\end{array}$ & $\begin{array}{c}\text { Obese } \\
\text { OSA } \\
\mathrm{n}=60\end{array}$ \\
\hline $\mathrm{NS} / V e r^{\circ}$ & $96.8 \pm 3.9$ & $98.0 \pm 7.7$ & $96.3 \pm 6.8$ \\
$\mathrm{NL}^{\circ}$ & $88.4 \pm 4.2$ & $89.9 \pm 7.5$ & $88.8 \pm 6.0$ \\
$\mathrm{NS} / \mathrm{OPT}{ }^{\circ}$ & $106.8 \pm 10.2$ & $105.8 \pm 8.5$ & $109.1 \pm 7.8^{\#}$ \\
$\mathrm{FH} / \mathrm{OPT}^{\circ}$ & $102.0 \pm 10.8$ & $100.9 \pm 7.8$ & $103.9 \pm 7.3^{\#}$ \\
$\mathrm{NL}^{\circ} \mathrm{OPT}{ }^{\circ}$ & $98.1 \pm 11.1$ & $97.2 \pm 7.1$ & $100.9 \pm 7.4^{\#}$ \\
OPT/Hor $^{\circ}$ & $79.9 \pm 10.2$ & $82.4 \pm 8.8$ & $77.8 \pm 8.7^{\#}$ \\
$\mathrm{CVT}^{\circ}$ Hor $^{\circ}$ & $81.5 \pm 11.7$ & $83.4 \pm 8.9$ & $78.6 \pm 8.9^{\#}$ \\
OPT/CVT $^{\circ}$ & $1.5 \pm 3.1$ & $0.9 \pm 1.9$ & $1.1 \pm 2.6$ \\
\hline
\end{tabular}

\#: $\mathrm{p}<0.02$ compared with non-obese OSA. For definitions see table 2 and text. 


\section{Relationship between AHI and cephalometric measure- ments}

The cephalometric measurements correlated with the AHI in the overall OSA patients and in the obese and nonobese patients are shown in table 7 . In the obese OSA patients, the AHI was correlated with the whole and inferior area of the tongue (Ton and Ton2), the length of the oropharynx (PNS-V), inferior and anterior displacement of the hyoid bone (MP-H and H-VL), anterior displacement of the mandible (G-VL) and the craniocervical angles (FH/OPT and NL/OPT), and inversely correlated with cranial base flexure (NSBa) and the cervical-horizontal angles (OPT/Hor and CVT/Hor). In the non-obese OSA patients, the AHI was correlated with the angle $\mathrm{BMeH}$, and inversely correlated with the anterior-posterior distance of the cranial base, maxilla and mandible (S-N, ANS-PNS and Me-Go).

Stepwise regressions on the AHI using the preselected variables were performed for the overall OSA patients and the different classes of BMI. For the overall patients, the regression model was significant $\left(n=78\right.$, model $r^{2}=0.421$, $\mathrm{F}=15.52, \mathrm{p}<0.0001)$ with the following determinants: HVL (partial $\left.\mathrm{r}^{2}=0.251, \mathrm{p}<0.0001\right)$, PNS-V (partial $\mathrm{r}^{2}=0.076$, $\mathrm{p}=0.028)$ and FH/OPT (partial $\left.\mathrm{r}^{2}=0.088, \mathrm{p}=0.020\right)$. In the non-obese OSA group, the model explained $23.4 \%$ of the variance of the AHI $(n=38, F=5.61, p=0.08)$ with two bony structure variables as the determinants: $\mathrm{S}-\mathrm{N}$ (partial $\left.r^{2}=0.131, p=0.018\right)$ and Me-Go (partial $\left.r^{2}=0.103, p=0.029\right)$. In the obese OSA patients, the regression model retained the only $\mathrm{H}-\mathrm{VL}$ and explained $38.1 \%$ of the variance of the AHI $(n=40, F=17.23, p=0.003)$. In this group, since $H-V L$ was significantly correlated with Ton $(\mathrm{r}=0.372, \mathrm{p}=0.043)$, Ton2 $(\mathrm{r}=0.450, \mathrm{p}=0.012), \mathrm{G}-\mathrm{VL} \quad(\mathrm{r}=0.6425, \mathrm{p}<0.0001)$, PNS-V ( $\mathrm{r}=0.370, \mathrm{p}=0.013), \mathrm{FH} / \mathrm{OPT}(\mathrm{r}=0.466, \mathrm{p}=0.009)$ and NL/OPT $(r=0.466, p=0.003)$ which were included in the pool of independent variables, the stepwise regression

Table 7. - Correlations of cephalometric measurements with apnoea-hypopnoea index in the overall obstructive sleep apnoea (OSA) patients, and the obese and non-obese OSA patients

\begin{tabular}{|c|c|c|c|}
\hline Parameters & $\begin{array}{l}\text { Overall } \\
\text { patients } \\
(n=114)\end{array}$ & $\begin{array}{c}\text { Non-obese } \\
\text { OSA } \\
(n=54)\end{array}$ & $\begin{array}{c}\text { Obese } \\
\text { OSA } \\
(n=60)\end{array}$ \\
\hline G-VL & $0.384 * * *$ & 0.002 & $0.421 * *$ \\
\hline $\mathrm{NSBa}$ & $-0.226^{*}$ & 0.118 & $-0.466 * *$ \\
\hline $\mathrm{S}-\mathrm{N}$ & 0.043 & $-0.277^{*}$ & -0.020 \\
\hline ANS-PNS & $-0.233^{*}$ & $-0.361^{*}$ & -0.194 \\
\hline Me-Go & -0.032 & $-0.274^{*}$ & -0.026 \\
\hline TGL & $0.213^{*}$ & -0.033 & 0.197 \\
\hline Ton & $0.317 * *$ & 0.112 & $0.295^{*}$ \\
\hline Ton2 & $0.351 * * *$ & -0.026 & $0.477 * * *$ \\
\hline MP-H & $0.310 * *$ & 0.011 & $0.490 * * *$ \\
\hline H-VL & $0.425 * * *$ & 0.195 & $0.386 * *$ \\
\hline BMeH & $0.269^{*}$ & $0.313 *$ & 0.171 \\
\hline PNS-V & $0.216^{*}$ & 0.105 & $0.302 *$ \\
\hline NS/OPT & $0.236 *$ & 0.172 & 0.251 \\
\hline FH/OPT & $0.371 * * *$ & 0.173 & $0.459 * * *$ \\
\hline NL/OPT & $0.347 * * *$ & -0.114 & $0.370 * *$ \\
\hline OPT/Hor & $-0.332 * * *$ & -0.115 & $-0.380 * *$ \\
\hline CVT/Hor & $-0.302 * *$ & -0.011 & $-0.324^{*}$ \\
\hline
\end{tabular}

All numbers are r-values. ${ }^{*}: \mathrm{p}<0.05 ;{ }^{* *}: \mathrm{p}<0.01 ; * *$ : $\mathrm{p}<0.001$ For definitions see table 2 and text. analysis was performed after excluding H-VL from the model. The regression model was still significant $(n=40$, model $\left.\mathrm{R}^{2}=0.384, \mathrm{~F}=8.403, \mathrm{p}=0.0015\right)$ with two determinants: Ton2 (partial $\mathrm{r}^{2}=0.240, \mathrm{p}=0.001$ ) and NSBa (partial $\left.\mathrm{R}^{2}=0.144, \mathrm{p}=0.014\right)$.

\section{Discussion}

The main finding of this study was that in comparison with BMI-matched normal subjects, the Japanese OSA patients presented a series of cephalometric abnormalities similar to those described in Caucasian patients [1-9]. Upper airway soft tissue enlargement, including enlargement of the tongue, soft palate and soft tissues surrounding the upper airway wall (ST(PNS-Ba)), was a dominant feature in the OSA patients. Even for those patients with a BMI $<27 \mathrm{~kg} \cdot \mathrm{m}^{-1}$ (non-obese), the tongue and soft palate were significantly enlarged compared with their BMImatched normal subjects. These findings are in accord with a previous notion that in most OSA patients, soft tissue abnormalities are more important than bony structure defects [6].

From a methodological viewpoint, the present work presents several advantages over previous studies of its kind. Firstly, since no systemic cephalometric study on Asian OSA patients has ever been reported in the English literature, 48 cephalometric variables in a large sample of 114 OSA patients were measured in order to obtain a thorough knowledge of the cephalometric features of the Japanese OSA patients. In addition, a well controlled normal group was employed for the non-obese OSA group: 19 of the 37 subjects $(51.4 \%)$ in the control group were confirmed negative for SDB by nocturnal polysomnogram. In the remaining 18 control subjects, the absence of SDB was documented by a detailed questionnaire concerning excessive daytime sleepiness, witnessed snoring and sleep apnoea. However, this control was not a good control group for the obese OSA patients because their weights were not well matched.

Secondly, it has been reported that cephalometric measurements change with age and BMI $[9,11]$. If so, it seems necessary that age and BMI be well matched when cephalometrics are to be compared between groups. With this in mind, the correlations between age and BMI and the cephalometric measurements were first examined. No significant correlations were found between age and any of the cephalometric variables used, while several variables were correlated with BMI. Therefore, subsequent comparisons were made primarily between BMI-matched groups.

Thirdly, considering that cephalometric landmark determinations and measurements may be prone to error, the reliability of cephalometric measurements was examined by calculating the $\mathrm{CV}$ for a group of representative variables, showing that the computer-assisted measurements were highly reproducible not only with a single observer (intraobserver reliability), but also with the multiple observers (interobserver reliability). To the authors' knowledge, such an estimation of reliability was performed in only one previous work and with a different method [12]. Ideally, reliability confirmation should be practised in cephalometric studies.

Finally, cephalograms were obtained using image plates and a computed radiography system. Using these new techniques, the cephalograms could be previewed on the 
computer screen and the contrast adjusted for clear observation of both the bony structures and the soft tissues before the images were printed on laser film, thus ensuring sharp visualization of the soft tissue contours, as well as the bony structures.

As shown in this study, there are clear differences in cephalometric measurements between OSA patients and healthy controls. However, from this data, a definite conclusion cannot be drawn as to whether a clear difference between the cephalograms of OSA patients and those of simple snorers, exists. MALTAIS et al. [13] found that the distance from the mandibular plane to the hyoid bone (MP$\mathrm{H})$ and the length of the soft palate were greater in OSA patients than in snorers. Significant differences between OSA patients and snorers were also found in the sagittal dimensions of the cranial base, maxilla and mandible by ZuCCONI et al. [14] in a small group of habitual snorers with and without OSA. On the contrary, there are reports which indicate that cephalograms of OSA patients and those of simple snorers do not differ from one another [6, 15]. The answer to this question must await a set of cephalometric measurements of a sufficient number of OSA patients and snorers whose degree of obesity is well-matched.

Two new soft tissue variables were employed in the present study: $\mathrm{BMeH}$ and Ton2. The authors believe that the angle $\mathrm{BMeH}$ best describes objectively the bird-like facial appearance [16] of OSA patients. In any case, it is clear from this data that the bird-like facial appearance observed in some OSA patients is determined by two factors: retrognathia and/or micrognathia, and/or inferior and anterior displacement of the hyoid bone. As has been suggested repeatedly [3, 13], inferior displacement of the hyoid bone may give rise to the inferior relocation of the tongue base and by so doing, compromise the upper airway patency. In this study, the inferior tongue area was measured directly and it was found that in both obese and non-obese OSA patients, the inferior tongue area was significantly enlarged when compared with normal subjects. Inferior tongue area measurement may bear more importance than overall tongue area measurement.

With regard to bony structure abnormalities in SDB patients, mandibular deficiency has been most frequently reported $[1,3,7]$. A new finding in this study is that the non-obese OSA patients in this series had relatively extensive facial compression, manifesting as a short cranial base, maxilla, mandible and bony pharynx width. The authors are aware of only two studies in which decreased bony dimensions of the upper airway were reported $[7$, 17]. In the present series, the shorter bony pharynx width may reflect a retroposition of the maxilla. Unlike mandibular retroposition that is usually observable on inspection, maxillary retrusion can only be detected with imaging. The narrowed bony inlet of the pharyngeal airway may, in fact, represent an inherited risk factor for the development of airway obstruction and deserves early detection. Furthermore, a careful evaluation of the bony pharynx width may be of importance in making therapeutic workups for OSA patients. Patients with a markedly narrowed bony pharynx, for instance, may be poor candidates for some surgical interventions aimed at upper airway soft tissue reduction. This study was performed on a consecutive, unselected group of OSA patients, and half of the patients in this series were not obese. Thus, this data suggest that in the Japanese population, where obesity is not as preva- lent as in the Caucasian population, craniofacial bony structure abnormalities are more severe and extensive and may play a more important part in the pathogenesis of OSA than in Caucasian patients.

A smaller SNB angle has long been used to indicate mandibular retrusion relative to the nasion $[1,2,5]$. In the present work, no significant difference was found in the SNB angle between the OSA patients and the normal controls, which was clearly due to the concomitant shortening of the cranial base in the OSA patients. Obviously, factors other than mandibular retrusion should be well controlled when explaining the significance of a decreased SNB angle.

The existence of distinct subgroups of SDB patients has been suggested by several investigators $[16,18]$. In the present study it was found that when compared with normal subjects, the non-obese group had both bony structure and soft tissue abnormalities, whereas the obese group exhibited predominantly soft tissue abnormalities. Comparison between the obese and non-obese patients indicated that the soft tissue abnormalities were more profound in the obese group and that the non-obese patients had a narrower facial A-P distance and a narrower bony pharynx than the obese patients. Furthermore, these results showed a clear distinction between the obese and non-obese OSA patients in terms of the correlation between cephalometric measurements and the severity of apnoea. In the nonobese OSA patients, the AHI was negatively correlated with the anterior cranial base length $(\mathrm{S}-\mathrm{N})$ and the mandibular length (Me-Go). No correlation was found between the AHI and any of the soft tissue variables in this group of patients. To the contrary, in the obese OSA patients, the AHI was significantly correlated with the anterior and inferior shift of the hyoid bone (H-VL and MP-H), tongue length (TGL), overall tongue area (Ton), inferior tongue area (Ton2), cranial base flexure angle (NSBa) and some head posture variables. The same result was obtained from stepwise regression analysis of AHI. For the non-obese OSA group, the regression model was significant with bony structure variables such as S-N and Me-Go. Although the regression model retained the only $\mathrm{H}-\mathrm{VL}$ as an explainable determinant for AHI in the obese OSA group, $\mathrm{H}-\mathrm{VL}$ was significantly correlated with several soft tissue variables such as Ton, Ton2, and PNS-V. When H-VL was not included in the analysis, the regression model was still significant with two determinants: Ton2 and NSBa. Thus, these data suggest that from a cephalometric point of view, the obese and non-obese OSA patients may have different pathogeneses. In obese patients, upper airway soft tissue enlargement may play a more important role in the development of OSA, whereas in non-obese patients, bony structure discrepancies may be the dominant contributing factors for OSA.

Significant differences in head postures have been reported by several groups [7, 19], suggesting that upper airway obstruction may lead to an increase in the craniocervical angulation. No significant differences in head posture variables between the non-obese OSA patients and BMI-matched normal controls were found. The obese OSA patients, however, had significantly greater craniocervical angles (NS/OPT, FH/OPT, and NL/OPT) and smaller cervical-horizontal angles (OPT/Hor and CVT/Hor) than the non-obese patients. A significant correlation was found between the AHI and some head posture variables in both the overall patients and the obese OSA group in this study. 
It should be noted that correlation analysis does not answer the question of cause-and-effect. Increase in craniocervical angulation and decrease in cervical-horizontal angulation may be a consequence rather than the cause of OSA [19]. Although there is no significant correlation between the head posture variables and BMI, this may simply indicate that a relationship between the degree of fat deposition around the neck, and body weight, does not exist. Therefore, the change in head posture could be attributed to obesity around the neck, rather than as a result of aggravation of upper airway obstruction. On the other hand, craniofacial bony structure defects are more likely causative factors for OSA, because craniofacial bony structures become stable from about 12 yrs of age [20].

The role of upper airway narrowing in the evolution of OSA has attracted much attention. Since narrowing may be present in various segments of the upper airway and not necessarily along arbitrarily preset lines, unlike other investigators, the narrowest part of the pharyngeal airway at two different levels (AW1 and AW2) in addition to the nasopharyngeal orifice and airway widths at the hypopharyngeal level were measured in the present study. These results confirmed previous findings that in both obese and non-obese OSA patients, there is extensive upper airway narrowing and significant reduction in the area of the oropharyngeal airway $[1,2,5]$. Apart from abnormalities in the upper airway dimension and area, these data suggest an elongation of the pharyngeal airway (PNS-V) in both obese and non-obese patients, which may have important pathophysiological consequences. PAE et al. [21] investigated the significance of pharyngeal length in 80 male OSA patients and discovered that the longer the pharynx, the more severe the sleep apnoea. The results of the present study also showed a weak correlation between AHI and PNS-V among all patients, and among the obese OSA patients. Also, the regression model of all patients showed that a significant correlation between AHI and PNS-V exists. It seems that elongation of the pharyngeal airway is a parameter which determines the severity of apnoea in at least some OSA patients. The significance of the upper airway elongation may be that as the pharynx becomes longer, the area of the upper airway subjected to soft tissue compression increases accordingly. This will be especially important during sleep in the supine position.

Apart from the well-recognized limitations of this method, where cephalograms are usually taken in the upright posture and awake state and are two-dimensional in nature, the clinical meaningfulness of group comparisons of cephalometric measurements is questionable. However, as has been reported by several investigators [3, 6-8], cephalometric measurement has clinical significance, in that it can be used for the evaluation of the pathogenesis and pathophysiology of OSA in a patient, and for the selection of the appropriate treatment modality.

In conclusion, this data indicate that: 1) in this Japanese population, the obstructive sleep apnoea patients had a series of cephalometric abnormalities similar to those described in Caucasian patients and Japanese obstructive sleep apnoea patients presented more comprehensive cra niofacial skeletal defects than Caucasian patients; and 2) the aetiology of obstructive sleep apnoea in obese patients may be different from that in non-obese patients from the perspective of cephalometric analysis.

\section{References}

1. Riley R, Guilleminault C, Herran J, Powell N. Cephalometric analysis and flow-volume loops in obstructive sleep apnea patients. Sleep 1983; 6: 303-311.

2. Jamieson A, Guilleminault C, Partinen M, Quera-Salva MA. Obstructive sleep apneic patients have cranio-mandibular abnormalities. Sleep 1986; 9: 469-477.

3. DeBerry-Borowiecki B, Kukwa A, Blanks RH. Cephalometric analysis for diagnosis and treatment of obstructive sleep apnea. Laryngoscope 1988; 98: 226-234.

4. Ferguson KA, Ono T, Lowe AA, Ryan CF, Fleetham JA. The relationship between obesity and craniofacial structure in obstructive sleep apnea. Chest 1995; 108: 375-381.

5. Hochban W, Brandenburg U. Morphology of the viscerocranium in obstructive sleep apnoea syndrome - cephalometric evaluation of 400 patients. J Craniomaxillofac Surg 1994; 22: 205-213.

6. Cistulli PA. Craniofacial abnormalities in obstructive sleep apnoea: implications for treatment. Respirology 1996; 3: 167-174.

7. Tangugsorn V, Skatvedt O, Krogstad O, Lyberg T. Obstructive sleep apnoea: a cephalometric study. Part I. Cervico-craniofacial skeletal morphology. Eur J Orthodontics 1995; 17: 45-56.

8. Tangugsorn V, Skatvedt O, Krogstad O, Lyberg T. Obstructive sleep apnoea: a cephalometric study. Part II. Uvulo-glossopharyngeal morphology. Eur J Orthodontics 1995; 17: 57-67.

9. Mayer P, Pepin JL, Bettega G, et al. Relationship between body mass index, age and upper airway measurements in snorers and sleep apnoea patients. Eur Respir $J$ 1996; 9: 1801-1809.

10. Ohta Y, Okada T, Kawakami Y, Suetsugu S, Kuriyama T. Prevalence of risk factors for sleep apnea in Japan: a preliminary report. Sleep 1993; 16: S6-S7.

11. Steinberg B, Fraser B. The cranial base in obstructive sleep apnea. J Oral Maxillofac Surg 1995; 53: 1150-1154.

12. Pracharktam N, Nelson S, Hans MG, et al. Cephalometric assessment in obstructive sleep apnea. Am J Orthod Dentofacial Orthop 1996; 109: 410-419.

13. Maltais F, Carrier G, Cornier Y, Series F. Cephalometric measurements in snorers, non-snorers, and patients with sleep apnoea. Thorax 1991; 46: 419-423.

14. Zucconi M, Ferini-Strambi L, Palazzi S, Orena C, Zonta S, Smirne S. Habitual snoring with and without obstructive sleep apnoea: the importance of cephalometric variables. Thorax 1992; 47: 157-161.

15. Andersson L, Brattström V. Cephalometric analysis of permanently snoring patients with and without obstructive sleep apnea syndrome. Int J Oral Maxillofac Surg 1991; 20: 159-162.

16. El-Sheikh MM, Medra AM, Warda MH. Bird face deformity secondary to bilateral temporomandibular joint ankylosis. J Craniomaxillofac Surg 1996; 24: 96-103.

17. Nelson S, Hans M. Contribution of craniofacial risk factors in increasing apneic activity among obese and non-obese habitual snorers. Chest 1997; 111: 154-162.

18. Tsuchiya M, Lowe AA, Pae E-K, Fleetham JA. Obstructive sleep apnea subtypes by cluster analysis. $\mathrm{Am} \mathrm{J}$ Orthofac Orthop 1992; 101: 533-542.

19. Solow B, Ovesen J, Niesen PW, Wildschiodtz G, Tallgren A. Head posture in obstructive sleep apnoea. J Orthodontics 1993; 15: 107-114.

20. Krogman WM. Forty years of growth research and orthodontics. Am J Orthod 1973; 63: 357-365.

21. Pae E-K, Lowe AA, Fleetham JA. A role of pharyngeal length in obstructive sleep apnea patients. Am J Orthod Dentofacial Orthop 1997; 111: 12-17. 